\section{First record of Liocheles nigripes Pocock, 1897 (Scorpiones: Hemiscorpiidae) from Andhra Pradesh with a checklist of scorpions of the state}

\author{
S.M. Maqsood Javed ${ }^{1}$, Zeeshan A. Mirza ${ }^{2}$, \\ Rajesh V. Sanap ${ }^{3} \&$ Farida Tampal ${ }^{3}$
}

1,2,3 World Wide Fund for Nature-India (WWF), APSO, 818, Castle Hills, Road No. 2, Near NMDC, Vijayanagar Colony, Hyderabad, Andhra Pradesh 500057, India.

Email: ${ }^{1}$ javedwwf2007@gmail.com, ${ }^{2}$ snakeszeeshan@gmail.com

The family Hemiscorpiidae consists of 12 genera and 80 species that inhabit all continents except North America with the majority of its diversity in tropical and subtropical habitats (Rein 2009). This family previously known as Ischnuridae Simon, 1879, has been renamed Liochelidae Fet \& Bechly, 2000 since it was homonymous with the

Date of publication (online): 26 March 2010

Date of publication (print): 26 March 2010

ISSN 0974-7907 (online) | 0974-7893 (print)

Editor: Vinod Khanna

Manuscript details:

Ms \# 02375

Received 29 December 2009

Finally accepted 08 February 2010

Citation: Javed, S.M.M., Z.A. Mirza, R.V. Sanap \& F. Tampal (2010). Firs record of Liocheles nigripes Pocock, 1897 (Scorpiones: Hemiscorpiidae) from Andhra Pradesh with a checklist of scorpions of the state. Journal of Threatened Taxa 2(3): 783-785.

Copyright: (c) S.M. Maqsood Javed, Zeeshan A. Mirza, Rajesh V. Sanap \& Farida Tampal 2010. Creative Commons Attribution 3.0 Unported License. JoTT allows unrestricted use of this article in any medium for non-profit purposes, reproduction and distribution by providing adequate credit to the authors and the source of publication.

Acknowledgements: The authors are very thankful to Shri Hitesh Malhotra, IFS, Principal Chief Conservator of Forests (Wildlife) and Chief Wildlife Warden, Andhra Pradesh; Shri. R. Hampaiah, Chairman and Shr V.B. Ramana Murthy, Member Secretary, Andhra Pradesh Biodiversity Board for their constant support and encouragement. We express our gratitude to Shri Anil Kumar V. Epur, Chairman, WWF-AP State Committee, Hyderabad and Shri Ravi Singh, Secretary General \& CEO WWF-India, New Delhi for their constant support and encouragement. We express our thanks to Shri Swaranjit Sen, IPS (Retd.), Chairman, Shri B. Venkatesham, IAS, Managing Director and Shri P.V. Ramana Reddy, IFS, Executive Director, Andhra Pradesh Tourism Development Corporation, Hyderabad for their constant support and for permitting us to conduct biodiversity studies in APTDC Eco-tourism sites. Special thanks to Aamod Zambre for constant support, encouragement and for providing valuable literature. ZM wishes to acknowledge the American Arachnological Society for a generous grant to carry out scorpion study and to Agarwal Jan Seva Charitable Trust for logistic support. Thanks are also due to Bhavans College for constant support, encouragement and lab facilities. We thank Mr. R. Sreekar and Mr. M. Seetharamaruju for participating in the survey. Lastly, we would like to thank Mr. P.S.M. Srinivas, Manager Corporate for exploring new places and all the WWF-Staff of APSO, Hyderabad for their constant support and timely suggestions.

\section{OPEN ACCESS | FREE DOWNLOAD}

damselfly subfamily Ishnurinae Fraser, 1957 (Fet \& Bechly 2000). Subsequently, Soleglad et al. (2005) again changed the name to Hemiscorpiidae. In India, this family is represented by three genera namely lomachus, Liocheles and Chiromachetes. Members of the genus Liocheles resemble lomachus but can be differentiated on the basis of the tarsi lacking a ventromedian series of small spinules between the setae (Image 4). The genus Liocheles Sundevall, 1833 is represented in India by two species L. nigripes Pocock, 1897 and L. australasiae Fabricius, 1775, both previously referred to the genus Hormurus Thorell, 1876. L. australasiae as well as $L$. nigripes are wide spread, the former being known from India to the western Pacific islands (Monod \& Volschenk 2004; Tikader \& Bastawade 1983; Sureshan et al. 2007) and the latter from parts of India, Laos, Vietnam, Indonesia and Malaysia (Kovařík 2000).

Liochelese nigripes was described by Pocock (1897) based on an immature specimen from Panch Mahal, Gujarat, India (Fet et al. 2000). Tikader \& Bastawade (1983) reported this species from Gujarat and Rajasthan. The species has been recently sighted in Chhattisgarh and the distribution includes Udaipur (Rajasthan), Panch Mahal (Gujarat), Almora (Uttarakhand), Gonda (Uttar Pradesh), Satna (Madhya Pradesh) and Kanger Valley National Park (Chhattisgarh) (Aamod Zambre pers. comm.). While conducting faunal surveys in Andhra Pradesh, several specimens of Liocheles nigripes (Images $2 \& 3$ ) were recorded from different parts (Araku Township, Hyderabad outskirts, Manchirial Town and Maredumilly) of the state (Image 1) and only two specimens were collected from Araku Township, Vishakapatnam District (18050'N \& $\left.79^{\circ} 42^{\prime} \mathrm{E}\right)$, near the Railway station on 28 February 2009 , and deposited in the collection of the Bombay Natural History Society as BNHS SC 35 and BNHS SC 36. This

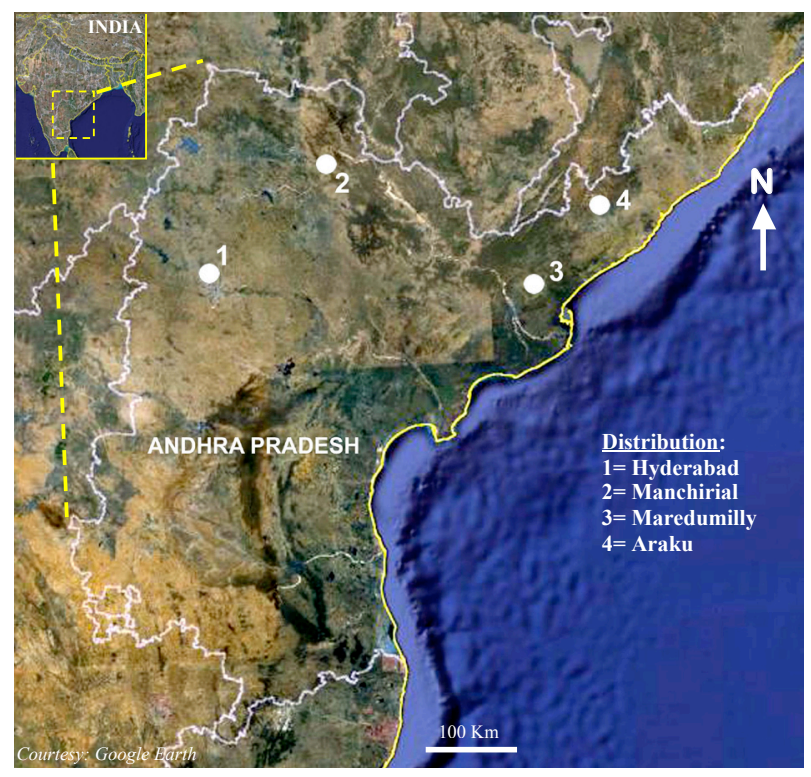

Image 1. Distribution of Liocheles nigripes in Andhra Pradesh. 

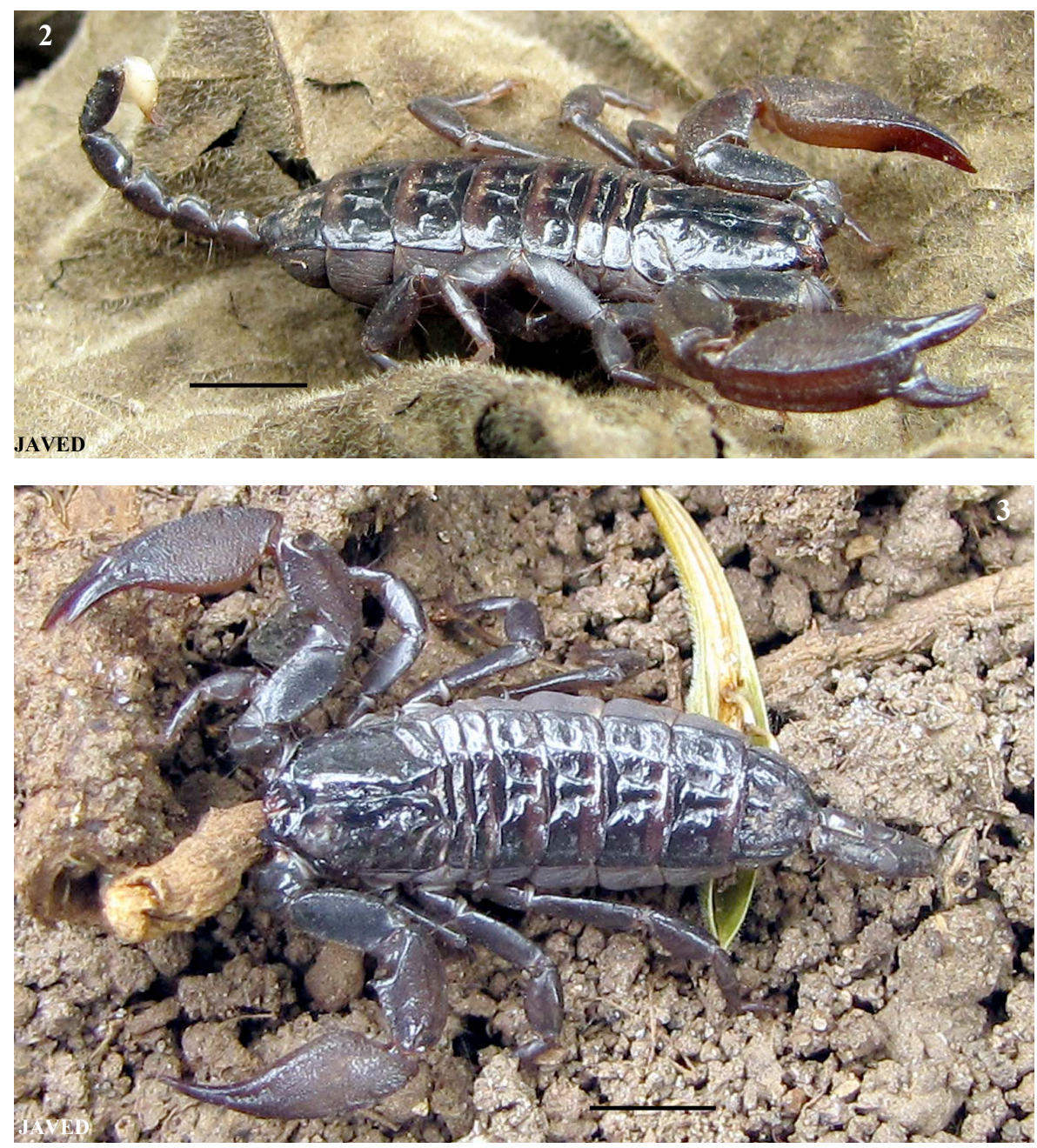

Images 2 \& 3. Liocheles nigripes (live) female (BNHS SC 35 \& 36)

2 - Lateral aspect; 3 - Dorsal aspect (scale $5 \mathrm{~mm}$ )

specimen represents the first record of this species from the state .

The present communication deals with the review of the distribution of this species and also provides an updated checklist of scorpions of Andhra Pradesh (Table 1).

The scorpion collected agrees well with the descriptions provided by Tikader \& Bastawade (1983) and Kovařík (2000), the detailed morphometry is provided in Table 2.

A review of the distribution of $L$. nigripes reveals it to be widespread in India as well which is supported by its occurrence in at least seven Indian states. Its occurrence in Gujarat, Uttarakhand, Uttar Pradesh, Madhya Pradesh, Chhattisgarh and Andhra Pradesh is suggestive of its occurrence in Bihar, Jharkhand, Maharashtra, Karnataka and Orissa. Furthermore, the record of Liocheles australasiae from Kerala by Sureshan et al. (2007) needs confirmation if it is indeed $L$. australasiae or $L$. nigripes which will shed light of its occurrence in Kerala and possibly Tamil Nadu.

The present record is not significant from a biogeographic point of view but it is a noteworthy contribution towards the study of Indian scorpions and their distribution on a broader scale as there is a distinct gap in distribution records of most species of scorpions and other arachnids, being merely known from either the type locality or a few scattered localities.

Rao et al. (2005) recorded seven species of scorpions whereas the recent literature review shows the state hosting at least eighteen species of scorpions (Table 1).

\section{References}

Fet, V. \& G. Bechly (2000). Case 3120. Ischnurainae Fraser, 1957 (Insecta, Odonata): proposed conservation as the correct spelling of Ischnurinae to remove homonymy with Ischnuridae Simon, 1879 (Arachnida, Scorpiones). Bulletin of the Zoological Nomenclature 57(1): 26-28.

Fet, V., W.D. Sissom, G. Lowe \& M.E. Braunwalder (2000). Catalog of the Scorpions of the World (1758-1998). The New York Entomological Society, 690pp.

Kovařik, F. (1997). Revision of the genera Lychas and Hemilychas, with description of six new species (Scorpiones: Buthidae). Acta Societatis Zoologicae Bohemicae 61: 311371.

Kovařík, F. (2000). First record of Liocheles nigripes from Indonesia and Malaysia and Hormiops davidovi from Malaysia (Scorpiones: Ischnuridae). Acta Societatis 
Table 1. Checklist of scorpions of Andhra Pradesh:

\begin{tabular}{ll}
\hline Species Checklist & Reference \\
\hline Buthidae & \\
Buthoscorpio sarassinorum (Karsch, 1891) & Rao et al. 2005 \\
Charmus indicus Hirst, 1915 & Tikader \& \\
Hottentotta stockwelli Kovařík, 2004 & Bastawade 1983 \\
Hottentotta rugiscutis (Pocock, 1897) & Kovařík 2007 \\
Hottentotta tamulus (Fabricius, 1798) & Kovařík 2007 \\
Isometrus thurstoni Pocock, 1893 & Kovařík 2007, \\
Isometrus khammamensis Kovaří, 2003 & Rao et al. 2005 \\
Isometrus corbeti Tikader \& Bastawade, 1983 & Kovařík 2003 \\
Isometrus vittatus Pocock, 1900 & Rao et al. 2005 2003 \\
Lychas tricarinatus Simon, 1884 & Rao et al. 2005 \\
Lychas scaber Pocock, 1893 & Kovařík 1997, \\
Hemiscorpiidae & Rao et al. 2005 \\
Iomachus nitidus Pocock, 1900 & Kovařík 1997 \\
Liocheles nigripes Pocock, 1897 & Kovařík 2004 \\
\hline Scorpionidae & Kovařík 2004 \\
Heterometrus fulvipes (C. L. Koch, 1837) 2004, \\
\hline
\end{tabular}

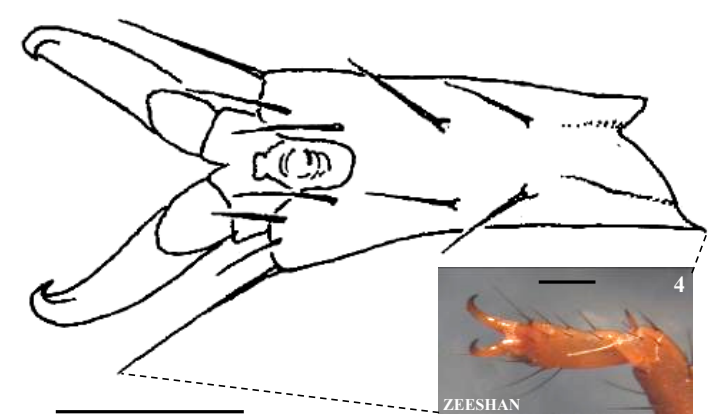

Image 4. Liocheles nigripes. Ventral aspect of tarsomere II of right leg IV, showing ventral submedian setae lacking row of small midventral spinules. (scale $1 \mathrm{~mm}$ )

Zoologicae Bohemicae 64: 57-64.

Kovařík, F. (2003). A review of the genus Isometrus Ehrenberg, 1828 (Scorpiones: Buthidae) with descriptions of four new species from Asia and Australia. Euscorpius - Occasional Publications in Scorpiology 10: 1-19.

Kovařík, F. (2004). A review of the genus Heterometrus Ehrenberg, 1828, with descriptions of seven new species (Scorpiones, Scorpionidae). Euscorpius - Occasional Publications in Scorpiology 15: 1-60.

Kovařík, F. (2007). A revision of the genus Hottentotta Birula, 1908, with descriptions of four new species (Scorpiones, Buthidae). Euscorpius - Occasional Publications in Scorpiology 58: 1-107.
Table 2. Morphometry of female Liocheles nigripes from Andhra Pradesh (measurements in $\mathrm{mm}$ ):

\begin{tabular}{lcc}
\hline Parameters & BNHS SC 35 & BNHS SC 36 \\
\hline Carapace Length & 6.65 & 7.19 \\
Carapace Anterior Width & 3.87 & 4.28 \\
Carapace Posterior Width & 6.11 & 6.89 \\
Mesosoma Length & 16.08 & 16.15 \\
Metasoma Length & 13.01 & 14.25 \\
Metasomal Segment I Length & 1.94 & 2.31 \\
Width & 1.54 & 1.62 \\
Metasomal Segment II Length & 2.23 & 2.52 \\
Width & 1.33 & 1.42 \\
Metasomal Segment III Length & 2.49 & 2.54 \\
Width & 1.31 & 1.52 \\
Metasomal Segment IV Length & 3.11 & 3.24 \\
Width & 1.33 & 1.41 \\
Metasomal Segment V Length & 3.24 & 3.64 \\
Width & 1.24 & 1.29 \\
Telson Length & 3.48 & 3.87 \\
Aculeus Length & 1.10 & 1.11 \\
Pedipalp Total Length & 23.75 & 26.19 \\
Pedipalp femur Length & 5.50 & 6.17 \\
Width & 2.58 & 2.77 \\
Pedipalp Patella Length & 6.21 & 6.37 \\
Width (max.) & 3.77 & 4.22 \\
Pedipalp Chelae Length & 12.04 & 13.65 \\
Width & 4.36 & 6.25 \\
Movable Finger Length & 5.64 & $6 / 6$ \\
Pectinal Teeth L/R & $6 / 6$ & \\
\hline & & \\
\hline
\end{tabular}

Monod, L. \& E.S. Volschenk (2004). Liocheles litodactylus (Scorpiones: Liochelidae): an unusual new Liocheles species from the Australian Wet Tropics (Queensland). Memoirs of the Queensland Museum 49(2): 675- 690.

Rao, K.T., \& D.B. Bastawade, M. Sudhakar, S.M.M. Javed \& I.S.R. Krishna (2005). Arachnid fauna of Nallamalai Region Eastern Ghats, Andhra Pradesh, India. Records of Zoological Survey of India. Occasional Paper 239: 1-42.

Rein, J.O. (2009). Scorpion Files. Norwegian University of Science and Technology, online at; http://www.ub.ntnu.no/ scorpion-files.

Soleglad, M.E., V. Fet \& F. Kovařík (2005). The systematic position of the scorpion genera Heteroscorpion Birula, 1903 and Urodacus Peters, 1861 (Scorpiones: Scorpionoidea). Euscorpius - Occasional Publications in Scorpiology 20: 1-38.

Sureshan, P.M., D.B. Bastawade \& C. Radhakrishnan (2007). Taxanomic studies on a collection of scorpions (Scorpiones: Arachnida) from Western Ghats in Kerala, India with two new distribution records. Zoos' Print Journal 22(12): 2903-2908.

Tikader, B.K. \& D.B. Bastawade (1983). Scorpions (Scorpionida: Arachnida), pp.499-510. In: The Fauna of India (Edited by the Director), Vol. 3. Zoological Survey of India, Calcutta, $671 \mathrm{pp}$. 